\title{
Bir Makine Fabrikasında Yarı Mamul Depolama Sistemi için Etkin Raf Yerleşimi Önerisi
}

\author{
Yeliz Buruk Şahin ${ }^{1 *}$, Sinem Ekmekçi², Melek Yürekli ${ }^{3}$ \\ ${ }^{1}$ Eskişehir Osmangazi Üniversitesi, Mühendislik Mimarlık Fakültesi, Endüstri Mühendisliği Bölümü, Eskişehir, TÜRKIYE (ORCID: 0000-0002-6215-5193) \\ ${ }^{2}$ Eskişehir Osmangazi Üniversitesi, Mühendislik Mimarlık Fakültesi, Endüstri Mühendisliği Bölümü, Eskişehir, TÜRKIYE (ORCID: 0000-0003-1546-6164) \\ ${ }^{3}$ Eskişehir Osmangazi Üniversitesi, Mühendislik Mimarlık Fakültesi, Endüstri Mühendisliği Bölümü, Eskişehir, TÜRKIYE (ORCID: 0000-0001-5064-104X)
}

(İlk Geliş Tarihi 7 Şubat 2020 ve Kabul Tarihi 19 Mart 2020)

(DOI: 10.31590 /ejosat.686494)

ATIF/REFERENCE: Şahin, Y. B., Ekmekçi, S. \& Yürekli, M. (2020). Bir Makine Fabrikasında Yarı Mamul Depolama Sistemi için Etkin Raf Yerleşimi Önerisi. Avrupa Bilim ve Teknoloji Dergisi, (18), 664-674.

Öz

Bu çalışmada, bir makine fabrikasındaki kaynak bölümünde bulunan yarı mamuller için etkin bir yerleşim düzeninin oluşturulması hedeflenmiştir. Firmada, yarı mamuller, kaynak bölümünde uzun süre kalmaktadır. Parçaların burada belirli bir yerinin olmaması, çalışanların bunları ararken vakit kaybetmesine sebep olmakta ve tezgâha taşıma mesafesini arttırarak değer katmayan faaliyetlerden kaynaklanan ek maliyetler oluşturmaktadır. Buradaki raf alanı yerleşimi probleminin çözümü için, tamsayılı matematiksel modellerden yararlanılmıştır. Bu modellerde, raf alanları ve taşıma aracı boyutları göz önüne alınarak parçaları oluşturacak yarı mamullerin raflara atanması yapılmaktadır. Yerleştirilmesi planlanan bu yarı mamullerin boyutları teknik resimler ve gerektiğinde parça üzerinden yapılan ölçümlere dayanarak belirlenmiştir. Kasa ve palet gibi taşıma araçlarının raflara yerleşimini yapmak üzere GAMS yazılımı ile iki ayrı model çözülmüştür. İlk model ile her bir raftaki parça çeşitliliğini en küçüklemek, ikinci modelde ise koridorlarda bulunan parça çeşitliliğini en küçüklemek hedeflenmiştir. Geliştirilen yaklaşımla, her bir parçanın yarı mamulleri için alternatif iki yerleşim düzeni önerilmiştir. Modellerin çözümüyle elde edilen sonuçlara göre ilk modelde raf doluluk oranı \%76,25, ikinci modelde ise \%78,47 olarak belirlenmiştir.

Anahtar Kelimeler: Tamsayılı Doğrusal Model, Raf Alanı Yerleşim Problemi, Üretim İçi Depolama Sistemi

\section{An Efficient Proposal for a Semi-Finished Product Storage System Shelf Assignment in a Machine Factory}

\begin{abstract}
In this study, an effective layout for semi-finished products of welding department in a machine factory is aimed. Presently, semifinished products are stored in this department for a long time. The absence of specific places for parts in process, cause waste of time for employees and excessive transfer distances to work centers. Consequently, redundant costs due to non-value added affairs arise. Two integer mathematical programming models are utilized to solve that shelf space allocation problem. The shelf areas and container sizes are taken into consideration in these models to determine the shelf assignments. The dimensions of these semi-finished products planned to be placed are determined by using of technical drawings and by direct measurements. Two different models have been solved with GAMS software to determine the placement of transport vehicles such as containers and pallets on the shelves. The first model aims to minimize the diversity of parts in shelves and the second model aims to minimize the diversity of the parts in the corridors. With the developed approach, two alternative layout plans for semi-finished products of each part is proposed. According to the results obtained by the solution of the models, the shelf occupancy rate became $76.25 \%$ in the first model and $78.47 \%$ in the second model.
\end{abstract}

Keywords: Integer Mathematical Model, Shelf Space Allocation Problems, Storage System in Production

\footnotetext{
1* Sorumlu Yazar: Eskişehir Osmangazi Üniversitesi, Mühendislik Mimarlık Fakültesi, Endüstri Mühendisliği Bölümü, Eskişehir, TÜRKIYE, ORCID: 0000-0002-6215-5193, yelizburuk@,ogu.edu.tr
} 


\section{Giriş}

Depolama faaliyeti, yarı mamullerin ve ürünlerin stoklanması amacıyla üretim ve sevkiyat süreçlerinde meydana gelebilecek sorunların önüne geçebilmek için kullanılmaktadır. Depoların ve dağıtım sistemlerinin planlanması, eniyilenmesi ve denetlenmesi depo yönetimi olarak ifade edilmektedir. Süreçler, ürünlerin depolama tesisine gelmesiyle başlamakta ve depolama tesisinden gönderilmesiyle sona ermektedir. Depo faaliyetlerinin başarısını ölçmek, etkinliğini ve verimliliğini arttırmak için birbirleriyle uyumlu depo yönetim sistemleri oluşturulmalıdır. Kullanım şekline göre depolar; hammadde, mamul ve karma depolar olmak üzere üçe ayrılır. Hammadde depoları, tedarik noktası ve üretim noktası arasında bulunan sadece hammadde ve yarı mamullerin depolandığ 1 tesislerdir. Mamul depoları, üretim yeri ve müşteri arasında bulunan tamamlanmış ürünlerin depolandığı tesislerdir. Karma depolar ise her iki şekilde kullanılan depolardır (Seval, 2018).

Üretim ve sevkiyat sürecinde istenilen malzemeye tam zamanında ulaşmak önemli bir faktördür. Depolama faaliyetinin etkin kullanılmaması, malzemenin istenilen zamanda tedarik edilememesine sebep olmaktadır. Dolayısıyla, bu durum üretim sürecinin aksamasına neden olmaktadır. İç lojistik faaliyetlerinin periyodik ve standart olması ile bu maliyet unsurlarının azalması hedeflenir. İstenilen malzemenin, istenilen yere istenilen zamanda ve miktarda götürülmesi süreçler arası stokları düşürürken, katma değeri olmayan faaliyetleri ve bunların maliyetlerini en aza indirmektedir (Küçükoğlu vd., 2018).

Tam zamanında üretim sisteminin temel özelliği süreç içi stokların azaltılmasını sağlamaktır. Süreç içi stoklar, üretim sistemini yavaşlatmakta, üretim sisteminin alanını işgal ederek gelişime kapatmakta ve aynı zamanda işletme sermayesinin bir kısmının atıl olarak bekletilmesi suretiyle firsat maliyetine yol açmaktadır (Sert ve Kesen, 2019). Tam zamanında üretim sisteminden esinlenerek, depolanan malzemenin belirli bir yerinin olması, çalışanların üretim alanını etkin kullanmalarını ve malzemelere istenilen zamanda ulaşmalarını sağlamaktadır. Depolama yönetim sistemleri farklı süreçler içerir. Bu süreçler sipariş toplama, aktarma, yükleme, palet ile taşıma ve istiflemedir. Eğer bu süreçler iyi analiz edilirse, analitik metotlar sayesinde önerilerde bulunulabilir (Yener ve Yazgan, 2019).

Bu çalışma, bir makine fabrikasının kaynak bölümünde etkin yerleşim sisteminin bulunmamasından ve yarı mamullerin dağınık istiflenmesinden kaynaklanan sorunların en aza indirilmesi amacıyla gerçekleştirilmiştir. Çalışmada, depolama problemi firmanın en belirgin darboğaz oluşan bölümünde ve ürününde ele alınmıştır. İstifleme süreci analiz edilerek, etkin yerleşim düzeninin oluşturulmasında matematiksel modelleme kullanılmıştır. Bu model oluşturulurken yarı mamul boyutlarının ve özelliklerinin göz önüne alınması gerekmiştir. Bu çalışmada oluşturulan matematiksel modelde kırılganlık ve ağırlık kısıtlarına, yarı mamuller arasında belirgin bir fark olmadığından, gerek duyulmamıştır. Bu yüzden çalışmada, sadece atama için kritik öneme sahip olan boyut kısıtları dikkate alınmıştır.

Bu makalenin, ikinci bölümünde literatür taraması, problemin tanıtımı ile materyal ve yönteme yer verilmiştir. Üçüncü bölümde, araştırma sonuçları ve kaynak bölümü için yerleşim önerileri sunulmuştur. Son bölümde ise sonuçlar ve önerilere yer verilmiştir.

\section{Materyal ve Metot}

\subsection{Literatür Taraması}

Depolama sistemlerinde malzemeye kolayca ulaşılması üretimin aksamaması için önemli bir ölçüttür. Literatürdeki mevcut çalışmalar; stok yerleştirme politikası, depolama sistemlerindeki başarı göstergelerinden biri olan raf alanı kullanımının en iyilenmesi ve katma değeri olmayan faaliyetlerin en küçüklenmesi yönüyle incelenmiştir.

Frazelle ve Sharp (1989)'a göre, grup tabanlı stoklama politikası, ürünler arasındaki olası ilişkileri göz önünde bulunduran bir stok atama politikasıdır. Petersen (1997)' e göre, paletler halinde ya da belirli miktarlarda gelen benzer ürün tipleri uygun olan boş depolama alanlarına eşit olasılıkla, rasgele yerleştirilir. Le-Duc (2005)' e göre en yakın boş alana yerleştirme politikası ile depoya gelen malzemeler ilk başta depodaki en yakın boş alana yerleştirilir. Atanmış veya sabit stok yerleşim politikasında, her bir ürün kendine ait olan alana yerleştirilir. Heragu vd. (2005) ürün yerleşimi ve depo tasarımı konusunda, her bir alanın boyutuna uygun ürün dağılımını belirleyen matematiksel bir model ile sezgisel bir algoritma geliştirmiştir. Tunç vd. (2008), depo raf sistemindeki sipariş çekme politikasını en iyileme konusunu ele almışlardır. İlk olarak, parçaların raflar içerisindeki konumlarını incelemiş ve en uygun toplama işlemi için mümkün olacak rotaları belirlemişlerdir. Taşıma zamanlarını ve maliyetlerini en küçüklemeyi hedefleyen en iyi rotalar için yeni bir depo yerleşimi önermiş ve sipariş toplama zamanlarını iyileştirmiş̧lerdir.

Surjandiri vd. (2012), perakende sektöründe raf alanı yerleştirme problemini, ürün kategorileri ve fiyatları arasındaki ilişkiden yola çıkarak veri madenciliği tekniğiyle çözmek üzere 0-1 tamsayılı bir matematiksel modelden yararlanmıştır. Kırış (2013)' e göre, ABC sınıflandırması uygulayan bir inşaat firmasında bulanık analitik ă̆ süreci (ANP) yaklaşımı ve geleneksel ABC analizini karşılaştırmıştır. Bulanık ANP yaklaşımı, ANP yönteminin belirsizliğini gidermek için uygulanmış ve belirsiz ortamlarda daha esnek karar verilmesi sağlanabilmiştir. Chabot vd. (2015), sipariş toplama problemini ağırlık, kırılganlık ve kategori kısıtları altında incelemiş, parçalar arası mesafenin en küçüklenmesini hedeflemişlerdir. Çözüm için, iki matematiksel model geliştirilmiş ve dört ayrı sezgisel model kullanılmıştır. Tekil ve Özkır (2016), bir filtre fabrikasının lojistik işlemlerini inceleyerek, ticari araçların ve konteynerlerin karmaşık yük ve yükleme planlarının en iyilenmesi için sezgisel bir algoritma kullanmışlardır. Gül vd. (2016), müşteri talepleri karşısında etkin depolamanın sağlanabilmesi amacıyla mamul ambarında en büyük depolama hacmi ve alanı sağlayacak şekilde, kasa tipleri ve hacimlerine göre ambarda ayrılacak alanları tespit etmişlerdir. Bu doğrultuda, farklı amaçlar çerçevesinde, problemin değişik versiyonları ardışık matematiksel modeller ile çözdürülmüştür. Problemin büyük boyutları için ise sezgisel bir algoritma geliştirilmiştir. Çolak vd. (2016), bir kimya firmasında kimyasal hammadde deposunun etkin yerleşimini sağlamak amacıyla iki aşamalı bir çözüm yaklaşımı önermiştir. İlk aşamada, çok ölçütlü ABC analizi yardımıyla en çok hareket eden hammaddeler belirlenmiştir. İkinci aşamada ise, bir matematiksel model geliştirilerek hammaddelerin taşınmasının en aza indirilmesi için, ABC analizi sonuçları kullanılarak bir 
yerleşim önerilmiştir. Zhou vd. (2017), çalışmalarında alan ve kapasite kısıtlarını dikkate almış, raf yerleşiminde RFID (Radio Frequency Identification) kullanan bir sistem önermişlerdir. RFID tarafından üretilen verilerle sağlanan gerçek zamanlı karar destek sistemine dayanan yeni bir esnek depolama tasarımı önerilmiştir. Petersen ve Aase (2017) tarafından yapılan çalışmada, çapraz toplama alanlarının sipariş toplama operasyonlarındaki yeri ve bunun çeşitli depolama faaliyetleri üzerindeki etkisi incelenmiştir. Sonuçlar, eşit ve düzensiz çapraz koridor yerleşiminin istatistiksel olarak farkll1ık göstermediğini ve çapraz koridorların eklenmesinin toplayıcı hareketini önemli ölçüde azalttığını göstermiştir. Küçükoğlu vd. (2018) ise, makinelere malzeme tedarik ederken, hat yanı stok miktarlarını ve taşıma maliyetlerini en küçüklemeyi hedeflemişlerdir. Bu amaç doğrultusunda, dolaşım mesafesini en küçükleyecek araç rotası oluşturulmuş, araç ve hat yanı stok miktarı kısıtlarını dikkate alan bir karışık tam sayılı doğrusal model geliştirilmiştir. Öztürkoğlu ve Hoşer (2018), depolarda sıklıkla kullanılan doğrusal düz orta ana koridorları, kesikli tüneller olarak tanımlayarak depolardaki ana koridorların yerleşim düzeni ile ilgili yeni bir tasarım geliştirmişlerdir. Tasarım problem için en iyi sipariş toplama rota uzunluğunu hesaplayabilmek amacıyla polinomsal zamanda dinamik programlama esaslı yeni bir algoritma önermişlerdir. Öztürkoğlu vd. (2018), depolamada zaman yönüyle en önemli faaliyet olan ürünlerin yerleştirilmesi ve toplanması konusunu ele alarak koridor tasarımı konusunda çalışmışlardır. Bu konuda Chevron tasarımını birçok farklı durumda inceleyerek geleneksel yerleşim ile karşılaştırmışlardır. Bu karşılaş̧ırma için problem, sürekli depo uzayında ve ayrık depo uzayında modellenmiş ve her iki uzaydaki depolar için ortalama seyahat mesafeleri belirlenmiştir. Öztürk vd. (2019), bir seramik fabrikasında ele alınan iki depo ve dört fabrika arasındaki taşıma mesafesini ve depodaki raf sayısını en aza indirmeyi hedefleyen bir depo yerleşim problemini ele almışlardır. Problemin çözümünde, çok amaçlı karma tamsayılı matematiksel model ve sezgisel algoritma kullanılmıştır. Kulaç ve Çağıl (2019), fabrika içerisindeki yarı mamul dağıtma işlemini araç rotalama problemine benzetmiştir. Kapasite kısıtlı araç rotalama problemi Clarke ve Wright tasarruf algoritması ve matematiksel model kullanılarak çözdürülmüştür. Sonuç olarak yarı mamul dağıtım operatörünün en kısa sürede çevrimini tamamlayacağı dağııım rotaları belirlenmiştir. Yılmaz Yalçıner ve Can (2019), gıda ambalajı üreten bir firmada yarı mamul deposunun kapasitesinin arttırılması ve ürünlerin boyutları göz önüne alınarak en iyi yerleşimin yapılması amaçlanmıştır. Verimli raf tipini belirlemek için sırt çantası modelinden, en iyi raf sayısını tespit etmek üzere tam sayılı programlama tekniğinden yararlanmışlardır. ProModel simülasyon programı ile mevcut ve önerilen sistem karşılaştırılmıştır. Denizhan ve Menşur (2019), bir lastik üretici firmasında, depodaki stok kapasitesi ve kapasite kullanımını etkin bir hale getirmeyi amaçlamışlar. Adresleme işlemini statikten dinamik düzene geçirmek amacıyla dinamik adresleme için bir algoritma önermişlerdir. Sonuç olarak, tedarik zinciri yönetiminin önemli bir parçası olarak; çeşitli ürünlerin dağıtılması, toplanması veya taşınmasının yanı sıra depolama sistemlerinin planlaması için de araştırmacılar çözüm önerileri geliştirmektedir.

\subsection{Problemin Tanıtılması}

Çalışma, yapılan gözlemler sonucunda firmada darboğaz oluşturduğu tespit edilen kaynak bölümünde gerçekleştirilmiştir. Üzerinde çalışılan ürün, talebi ve firmaya olan kazancı yüksek olması itibariyle seçilmiştir. Firmada kaynak bölümünde, sürekli bir besleme sistemi olmayıp kaynaktaki yarı mamul bittikçe şekillendirme bölümünden yarı mamul beslemesi beklenmektedir. Gelen yarı mamuller belli bir taşıma aracıyla ve belirli bir rafa gelmemektedir. Mevcut sistemde, kaynak bölümüne gelen yarı mamuller, boyutlarına dikkat edilmeden boşta olan taşıma aracıyla (kasa veya palet ile) depolanmaktadır. Taşıma araçlarının üzerinde barkod veya KANBAN kartları gibi ürünün özelliğini belirtecek açık bir sistem bulunmamaktadır. SAP işlem çıktısı parçaların üzerine koyularak taşıma yapılmaktadır. Bu süreç, iş̧̧inin kaynak alanındaki yarı mamulün hangi rafa yerleşmesi gerektiğini anlaması için ciddi bir zaman kaybı oluşturmaktadır. $\mathrm{Bu}$ sürecin zorluğu ve yerleşimin belirsizliği nedeniyle, iş̧̧i gelen yarı mamulü ilk bulduğu boş rafa yerleştirmektedir. Şekillendirme bölümünden gelen yarı mamuller, kaynak bölümünde sekiz ayrı hücrede işlenmektedir. Son hücre olan dokuzuncu hücrede ise, son kaynak işlemleri yapılarak kaynak bölümündeki süreç sonlanmaktadır.

Hücrelere gelen yarı mamullerin doğru olması, üretim sürecinin başarısı için önemli bir ölçüttür. Ancak, gelen yarı mamullerin sabit bir yerleşim düzeninin bulunmaması üretim içerisinde zaman kaybına, yanlış yarı mamulün kaynak işlemine tabi tutulmasına ve sonuç olarak yarı mamul kayıplarına yol açmaktadır. Firmada, parçaların karışık yerleşiminin engellenmesi için ihtiyaç duyulan alan ve raf gereksinimine yönelik bir çalışma bulunmamaktadır. Yerleşemeyen parçalar raf önlerinde ya da kaynak hücrelerinde yerde beklemektedir. Bu çalışmada, literatürdeki çalışmalardan esinlenerek mevcut probleme çözüm önerileri sunulmuştur. Firmada mevcut durumda, yerleşimde kullanılabilecek taşıma araçlarının boyutlarına Tablo 1'de yer verilmiştir. Parçaların yarı mamulleri fabrika bünyesinde bulunan dört tip taşıma aracı boyutları göz önüne alınarak Excel’de listelenmiş̧ir.

Tablo 1. Taşıma Araçları Boyutları (mm)

\begin{tabular}{ccc}
\hline Mevcut taşıma araçları & X (En) & Y (Boy) \\
\hline Kasa tipi 1 & 195 & 150 \\
Kasa tipi 2 & 390 & 150 \\
Kasa tipi 3 & 390 & 300 \\
Palet & 1200 & 500 \\
\hline
\end{tabular}

Raf alanı yerleşim probleminin çözümü için ilk aşamada, son ürün için gerekli parçalar ve her bir parçanın yarı mamulleri ürün ağacı üzerinden çekilerek listelenmiş̧ir. Tablo 2 'de her bir parçanın taşıma araçlarına göre dağılımına yer verilmiş olup, görüldüğü gibi toplam 155 yarı mamul bir araya gelerek son ürünü oluşturmaktadır. Bu yarı mamuller, işlem görecekleri hücreler doğrultusunda 9 gruba ayrılmıştır. Yarı mamullerin boyutları teknik resimler yardımı ile x (en) ve y (boy) olmak üzere belirlenmiş̧ir. 
European Journal of Science and Technology

Tablo 2. Parçaların Taşıma Araçları Temelinde Dă̆ılımı

\begin{tabular}{cccccc}
\hline & \multicolumn{5}{c}{ Taşıma Araçları } \\
\hline Parça no & Toplam yarı mamul & Kasa1 & Kasa 2 & Kasa 3 & Palet \\
\hline 1 & 5 & 3 & 0 & 1 & 1 \\
2 & 16 & 8 & 0 & 8 & 0 \\
3 & 16 & 7 & 0 & 9 & 0 \\
4 & 9 & 3 & 3 & 2 & 1 \\
5 & 15 & 6 & 0 & 9 & 0 \\
6 & 7 & 3 & 0 & 4 & 0 \\
7 & 28 & 18 & 1 & 8 & 1 \\
8 & 22 & 13 & 0 & 8 & 1 \\
9 & 37 & 13 & 1 & 16 & 7 \\
Toplam yarı mamul & 155 & 74 & 5 & 65 & 11 \\
\hline
\end{tabular}

Bu gözlemden yola çıkılarak tek bir ürünün üretimi için gerekli yarı mamul/taşıma aracı ataması, teknik resimlerden elde edilen boyutlar ve yapılan ölçümler doğrultusunda gerçekleşmiştir. Yerleşimde dikkate alınan yarı mamullerin büyüklüklerinin taşıma aracı boyutlarını aşmadığı gözlenmiştir. Problemin çözümünde yarı mamullerin taşıma araçlarına atanmasından sonra yarı mamul boyutları göz ardı edilerek, yerleşimde taşıma araçları boyutları kullanılmıştır. Yerleşim yapılırken, rafların ve taşıma araçlarının boş olduğu varsayılmaktadır. Yarı mamullerin ağırlıkları arasında anlamlı fark bulunmamaktadır, bu sebeple ağırlık kısıtı göz ardı edilmiştir.

\subsection{Materyal ve Yöntem}

Mevcut taşıma aracı sayısı göz önüne alınarak raf yerleşimi, literatürde önerilen modellerden hareketle geliştirilen matematiksel modeller yardımıyla çözülmüştür. İlk modelde, raflardaki parça çeşitliliğinin en küçüklenmesi amaçlanmaktadır. Parçaların dağınık yerleşimi ve taşıma mesafesi göz önüne alınarak geliştirilen ikinci modeldeki amaç ise, koridorlardaki parça çeşitliliğinin en küçüklenmesidir.

\subsubsection{Kasa-raf Yerleștirme Modeli}

Firmada sabit bir yerleşim düzeni bulunmadığından taşıma araçlarının bir kısmı üretimin içerisinde işçilerin çalışma alanını kısıtlayacak şekilde hücre kenarlarında depolanmıştır. Bu durumun önüne geçmek amacıyla, bütün taşıma araçlarının raflarda depolanması öncelik taşımaktadır. Parça tabanlı kasa-raf yerleştirme modeli ile her bir raftaki parça çeşitliliği en küçüklenerek sabit bir yerleşim düzeninin oluşturulması amaçlanmıştır. Modelin çözümünde, Tablo 2'deki taşıma aracı sayıları girdi olarak kullanılmıştır.

\section{İndisler}

$$
\begin{array}{ll}
p=\text { parça } & (1, \ldots, P) \\
k=\text { koridor } & (1, \ldots, K) \\
i=\text { taşıma aracı tipi } & (1, \ldots, I) \\
j=\text { raf } & (1, \ldots, J)
\end{array}
$$

\section{Parametreler}

$R G_{k j}=k$. koridorun $j$. rafının genişliğ $i$

$K G_{p i}=p \cdot$ parçanın $i$.tip taşıma aracının genişliğ $i$

$C=$ üst üste yerleştirilme adedi (3 adet)

$K S_{p i}=p$. parçanın i.tip taşıma aracından depolanması gerekli miktar

$M=$ çok büyük bir sayı

\section{Karar Değişkenleri}

\section{İkili (Binary) Değişken}

$M K_{p j}=\left\{\begin{array}{l}1, \mathrm{p} \cdot \text { parça } \mathrm{j} \cdot \text { rafa yerleştiriliyorsa } \\ 0, \mathrm{dd}\end{array}\right.$

\section{Tam Sayılı Değissken}

$X_{\text {pikj }}=$ p.parçanın $i$.tip taşıma aracının $k$. koridorun $j$. rafına yan yana yerleştirilme adedi 


\section{Amaç Fonksiyonu}

$\operatorname{Min} Z=\sum_{p=1}^{P} \sum_{j=1}^{J} M K_{p j}$

\section{Kisitlar}

$$
\begin{array}{ll}
R G_{k j}-\sum_{i=1}^{I} K G_{p i} * X_{p i k j} \geq 0 & \forall_{k, j} \\
M K_{p j} * M \geq \sum_{i=1}^{I} \sum_{k=1}^{K} X_{p i k j} & \forall_{p, j} \\
\sum_{k=1}^{K} \sum_{j=1}^{J}\left(C * X_{p i k j}\right) \geq K S_{p i} &
\end{array}
$$

Modeldeki C parametresi firmada depolama amacıyla kullanılan raflar 3 katlı olduğu için “3” olarak alınmıştır. Üst üste koyulma sayısı rafların katlarını belirtmektedir. Modelde amaç, raflardaki parça çeşitliliğinin en küçüklenmesidir (2.1). Kısıt (2.2), her tip taşıma aracının toplam genişliğinin raf genişliğini aşamayacağını ifade etmektedir. Kısıt (2.3), eğer bir tip parçaya ait bir taşıma aracı bir rafa yerleştiriliyorsa, o rafta o parçaya ait atanmış yarı mamullerin sayısını ifade etmektedir. Kısıt (2.4) ise raflara atanması gereken taşıma aracı adet hedefini sağlamaktadır.

Matematiksel model GAMS yazılımı CPLEX çözücüsü kullanılarak çözdürülmüştür. Ek 1 ve Ek 2' de görüldüğü gibi, ele alınan modelde koridor-raf ilişkisi 1. koridorda 4 raf, 2. koridorda 2 raf, 3. koridorda 4 raf olarak alınarak kurulmuştur.

\subsubsection{Kasa-koridor Yerleștirme Modeli}

Kasa- raf yerleştirme modelinde raflardaki parça çeşitliliği en küçüklenmiş ancak parçaların taşıma araçları farklı koridorlara da yerleştirilebildiği gözlenmiştir. İlk modelin sonucu olarak işçiler yarı mamullerin yerini kolayca bulabilmektedir. Ancak, farklı koridorlarda depolanan yarı mamulleri hücrelere aktarırken taşıma mesafesini arttırabildiği gözlenmiştir. Bu gözlemden yola çıkarak koridordaki parça çeşitliliğinin en küçüklenmesi amaçlanarak parça tabanlı kasa- koridor yerleştirme modeli oluşturulmuştur.

Kullanılan iki model amaç fonksiyonları dışında birebir benzerlik göstermektedir. Bu nedenle indis, parametre ve tam sayılı değişken tanımlamaları yenilenmemiştir.

\section{Karar Değişkenleri \\ İkili (Binary) Değişken}

$M K_{p k}=\left\{\begin{array}{c}1, \text { p. parça k. koridora yerleştiriliyorsa } \\ 0, \text { dd }\end{array}\right.$

\section{Amaç Fonksiyonu}

$\operatorname{Min} Z=\sum_{p=1}^{P} \sum_{k=1}^{K} M K_{p k}$

\section{Kisitlar}

$$
R G_{k j}-\sum_{i=1}^{I} K G_{p i} * X_{p i k j} \geq 0 \quad \forall_{k, j}
$$




$$
M K_{p k} * M \geq \sum_{i=1}^{I} \sum_{k=1}^{K} X_{p i k j} \quad \forall_{p, j}
$$

$$
\sum_{k=1}^{K} \sum_{j=1}^{J}\left(C * X_{p i k j}\right) \geq K S_{p i} \quad \forall_{p, i}
$$

Modelde amaç, koridorlardaki parça çeşitliliğinin en küçüklenmesidir (2.5). Kısıt (2.6), her tip taşıma aracının toplam genişliğinin raf genişliğini aşamayacağını ifade etmektedir. Kısıt (2.7), eğer bir tip parçaya ait bir taşıma aracı bir koridora yerleştiriliyorsa, o koridorda o parçaya ait atanmış yarı mamullerin sayısını ifade etmektedir. Kısıt (2.8) ise rafa atanması gereken taşıma aracı adet hedefini sağlamaktadır. Bu durumda, koridorda bulunan parça çeşitliliği azaldığından işçinin, bir parça için farklı koridorlardan yarı mamul almasına gerek kalmamış ve taşıma mesafesi azalmıştır.

\section{Araştırma Sonuçları ve Tartışma}

Her iki modelin GAMS çıktılarına göre, taşıma araçlarının raflara yerleşimleri, bu bölümde örneklenerek açıklanacaktır.

\subsection{Kasa-raf Yerleşim Modeli}

Her bir parçanın raflara yerleştirilmesine dayanan modelde; 1. koridorun 1. rafina Şekil 1' de gösterildiği gibi 1. 7. ve 9. parçalar yerleştirilmiştir. Sözü edilen birinci raf yerleşiminde, kasaların yatay eksende kapladığı uzunluk 2340 mm'dir. (Katlar aşağıdan yukarıya doğru 1.kat, 2. kat ve 3. kat olarak isimlendirilmektedir).

Taşıma araçlarının boyut toplamının raf boyutunu aşmadığı doğrulanmış olup kapasitenin aşılmadığı, verilerden yararlanarak doğrulanmıştır. Rafların doluluk oranına bakıldığında ise birbirine yakın değerler olduğu ve bu durumda olabildiğince az raf sayısının

\begin{tabular}{|c|c|c|c|c|c|c|c|c|c|c|}
\hline \multicolumn{10}{|c|}{ 1.KORIDORUN 1.RAFI } & \multirow{2}{*}{\begin{tabular}{|r|} 
DOLULUK $(\%)$ \\
$2340(\% 97,5)$
\end{tabular}} \\
\hline $\mathrm{P7}(\mathrm{K} 3)$ & P7(K 3) & P7(K 3) & $\mathrm{P} 7(\mathrm{~K} 1)$ & \multicolumn{3}{|c|}{$\mathrm{P} 7(\mathrm{~K} 3)$} & \multicolumn{2}{|c|}{$\mathrm{P} 7(\mathrm{~K} 3)$} & $\mathrm{P9}$ (K 1) & \\
\hline $\mathrm{P} 7(\mathrm{~K} 3)$ & $\mathrm{P} 7(\mathrm{~K} 3)$ & $\mathrm{P} 7(\mathrm{~K} 3)$ & P7(K 1) & \multicolumn{2}{|c|}{$\mathrm{P} 7(\mathrm{~K} 1)$} & & P7(K 1) & \multicolumn{2}{|c|}{$\mathrm{Pg}(\mathrm{K} 1)$} & $2340(\% 97,5)$ \\
\hline \multicolumn{2}{|l|}{ P1(Palet) } & & \multicolumn{2}{|c|}{$\mathrm{P7}(\mathrm{K} 1)$} & $\mathrm{P7}$ (K 1) & $\mathrm{P7}(\mathrm{K} 1)$ & $\mathrm{P} 7(\mathrm{~K} 1)$ & $\mathrm{P7}$ (K 1) & $\mathrm{P} 7(\mathrm{~K} 1)$ & $2370(\% 98,75)$ \\
\hline
\end{tabular}
kullanıldığı gözlenmiştir. Raflardaki boş alanlar uygun taşıma aracı bulunamadığından oluşmaktadır.

Şekil 1. 1.Koridor Yerleşimine Ait Parça Bazlı Yerleşim Düzeni

Raf ve koridor temelinde elde edilen doluluk oranları Ek-1'de gösterilmiştir. Doluluk oranları, yerleştirilen taşıma araçlarının genişlikleri ve raf genişliği göz önüne alınarak hesaplanmıştır. Yapılan yerleşimde, model sonuçlarına göre \% 76,25'lik ortalama doluluk oranı bulunmuştur.

Tablo 3. Parça Bazlı Kasa-Raf Yerleşimi Doluluk Oranları

\begin{tabular}{cc}
\hline Parça No & (Koridor No, Raf No) \\
\hline 1 & $(1,1),(2,1)$ \\
2 & $(1,3)$ \\
3 & $(3,3)$ \\
4 & $(1,2),(2,2)$ \\
5 & $(1,2),(2,2)$ \\
6 & $(1,3),(3,3)$ \\
7 & $(1,1),(2,1)$ \\
8 & $(2,2),(3,2),(1,1)$ \\
9 & $(1,4),(3,1),(3,4)$ \\
\hline
\end{tabular}

Tablo 3' teki yerleşimler incelendiğinde parçaların koridorlardaki raflara dağılımı görülmektedir. Örneğin 1. parçaya ait taşıma araçları iki ayrı koridorda yer almaktadır. 9. parçanın ise iki ayrı koridorda farklı raflara yerleşimi görülmektedir. Bunun sebebi 9. parçanın bağlantı elemanı olması ve birçok alt işlemde uygulanan yarı mamullerden oluşmasıdır. Kasa-Raf yerleşim model çözüm raporuna göre yapılan atamaların tamamı Ek 1'de sunulmuştur. 


\subsection{Kasa- Koridor Yerleşim Modeli}

Her bir parçanın koridorlardaki raflara yerleştirilmesine dayanan modelde 1. koridorun 1. rafina ait olan yerleşim düzeni GAMS modelinin çıktılarına göre Şekil 2'de verildiği gibidir.

\begin{tabular}{|c|c|c|c|c|c|c|c|}
\hline \multicolumn{7}{|c|}{ 1.KORIDORUN 1.RAFI } & \multirow{3}{*}{$\begin{array}{l}\text { Doluluk (\%) } \\
2370(\% 98,75) \\
\end{array}$} \\
\hline & & & & \multirow{2}{*}{\multicolumn{3}{|c|}{ P8 (Palet) }} & \\
\hline $\mathrm{P} 1$ (K 1) & $\mathrm{P7}(\mathrm{K} 3)$ & P7 (K 3) & $\mathrm{P} 8(\mathrm{~K} 1)$ & & & & \\
\hline $\mathrm{P} 1$ (K 1$)$ & $\mathrm{P5}(\mathrm{K} 3)$ & P7 (K 3) & P7 (K 3) & P7 (K 3) & $\mathrm{P} 8(\mathrm{~K} 1)$ & $\mathrm{P} 5$ (K 3) & $2340(\% 97,5)$ \\
\hline P1 (K 1) & P5 (K 3) & P7 (K 3) & P7 (K 3) & P7 (K 3) & $\mathrm{P} 8$ (K 1) & P5 (K 3) & $2340(\% 97,5)$ \\
\hline
\end{tabular}

Şekil 2. 1.Koridorun 1.Rafina Parçaların Yerleşimi

Raflara yerleşim Tablo 2'de verilen parça isimleri kullanılarak yapılmıştır. Parça tabanlı kasa-koridor yerleşimi doluluk oranları Ek 2'de verilmiştir. Yerleşim sonuçlarına bakıldığında, ortalama \%78,47’lik raf doluluk oranı sağlanmıştır. İlk modelle karşılaştırıldığında ortalama raf doluluk oranının arttığı gözlenmektedir. İkinci model aracılığıyla elde edilen çıktı sonucu koridorlara yerleşen parçalar Tablo 4'te gösterilmiştir.

Tablo 4. Koridorlara Yerleşen Parça Tipleri

\begin{tabular}{cc}
\hline Koridor No & Parça Tipi \\
\hline 1 & $1,5,7,8$ \\
2 & $2,3,6$ \\
3 & 4,9 \\
\hline
\end{tabular}

Tablo 4 incelendiğinde, parçaların yarı mamullerinin aynı koridorda bulunduğu gözlenmiştir. Bu modelin amacı koridorlardaki parça çeşitliliğini en küçüklemek olduğundan bir koridorda bulunan parça diğer koridorlara yerleştirilmemiştir. Bu yerleşim düzeni ile işçinin hem taşıma aracını aramasından kaynaklı zaman kaybı hem de taşıma aracının üretim alanına taşımasından kaynaklı zaman kaybı önlenmiş olacaktır. Raflarda boşlukların oluşmasının önemli nedeni bu durumdur. Siparişe dayalı üretim yapıldı̆̆ı için, parçalara ek yarı mamuller eklenmesi durumunda taşıma araçlarına yerleşememe durumu engellenmiştir. Kasa-Koridor yerleşim model çözüm raporuna göre yapılan atamaların tamamı Ek 2'de sunulmuştur.

Parça tabanlı kasa-raf yerleştirme modeline göre mevcut sistemde, bir işçinin günde ortalama 30 dakikasını parça aramak için geçirdiği gözlemlenmektedir. Bu gözlemler sonucunda, fabrikada haftada 5 gün çalışıldığı göz önüne alınarak işçinin haftalık 2 saat 30 dakikalık çalışma süresinin parça aramakla geçtiği hesaplanabilmektedir. Her bir ana parçanın kaynaklanması için hücrede 1 işçinin çalıştığı, toplamda son ürün için 9 işçinin çalıştığ göz önüne alınarak haftada 22 saat 30 dakikalık bir süre parça aramakla geçtiği söylenebilir. Belirtilen süreler, haftalık çalışma saatinin 40 saat olduğu bir işletme için büyük kayıplardır. Yapılan çalışma ile bu kayıpların büyük kısmının önleneceği görülmektedir. Yapılan çalışma sonucunda, gelen yeni sipariş veya parça adetlerinde artış olma durumunda yarı mamullerin rafların dışında kalması engellenerek esnek bir yerleşim düzeni oluşturulmuştur.

Parça tabanlı kasa-koridor yerleştirme modeline göre ise mevcut sistemde, bir işçinin günde ortalama 30 dakikasını parça aramak için geçirdiği ve işçinin taşıma aracını bulduktan sonra parçayı kendi kaynak kolaylığının bulunduğu alana taşıması için günde ortalama 15 dakikasını geçirdiği gözlemlenmektedir. Bu gözlemler sonucunda, işçinin uygun parçayı aramak için geçirdiği zamana ek olarak, işçinin raf alanından üretim hücresine yarı mamulleri taşıması için geçen süre günlük 15 dakika olarak gözlenmiştir. Bu süre doğrultusunda, haftada 5 iş gününde 1 saat 15 dakikalık çalışmanın boşa geçtiği hesaplanmaktadır. 9 işçi için bu süre 10 saat 35 dakika olarak hesaplanmaktadır. Toplamda, işçi hem parçayı arayıp hem de uygun alana taşımayı gerçekleştirdiği için 33 saat 5 dakikalık bir zaman kaybı oluşması öngörülmektedir. Önerilen parça tabanlı kasa-koridor yerleşiminin yapılması sonrasında aynı tip parçaların raf ve koridorlarda sabit yerleşiminin sağlanması ile yukarıda hesaplanan zaman kayıplarının büyük çoğunluğunun önüne geçilebileceği söylenebilir.

İki model kazanılabilir süre yönüyle karşılaştırıldığında Şekil 3’teki grafik elde edilmiştir. Grafikte, x ekseninde işçi sayıları, y ekseninde ise dakika cinsinden süreler verilmiştir. 
European Journal of Science and Technology

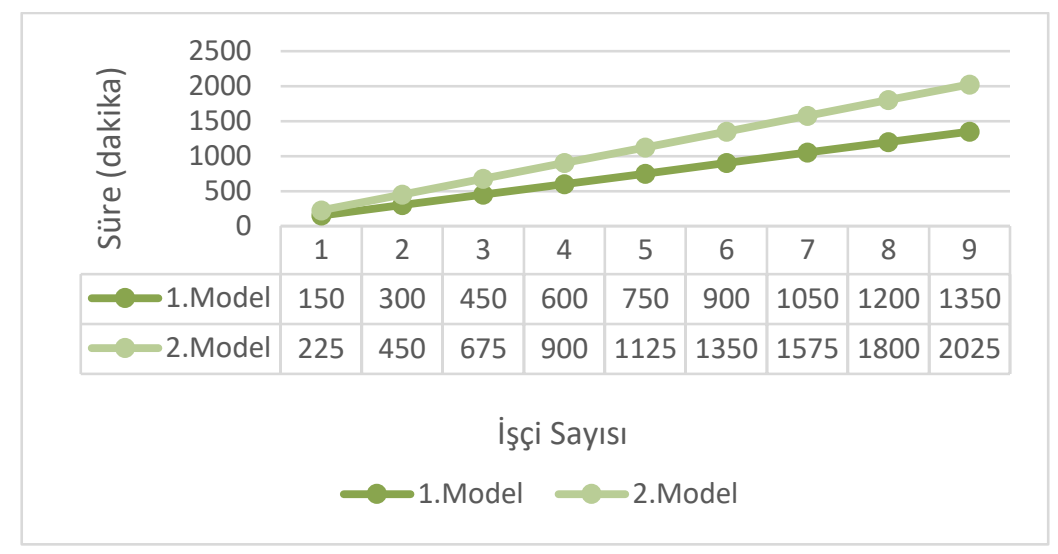

Şekil 3. Modellerin Süre Yönüyle Karşılaştırılması

Grafiğge göre, 1. model ile her bir taşıma aracı için sabit bir yerleşim sonucunda işçinin parçayı araması için kaybettiği sürelerin büyük çoğunluğunun önüne geçileceği öngörülmektedir. 2. model aracılığıyla, hem her bir taşıma aracının sabit bir yerleşimi sağlanmış, hem de parçaların dağınık yerleşimin önüne geçilerek işçinin parça arama ve taşıma sürelerinden kaynaklı kayıpların büyük çoğunluğunun önleneceği öngörülmektedir.

İki model maliyet yönüyle karşılaştırıldığında ise Şekil 4’teki grafik elde edilmiştir.

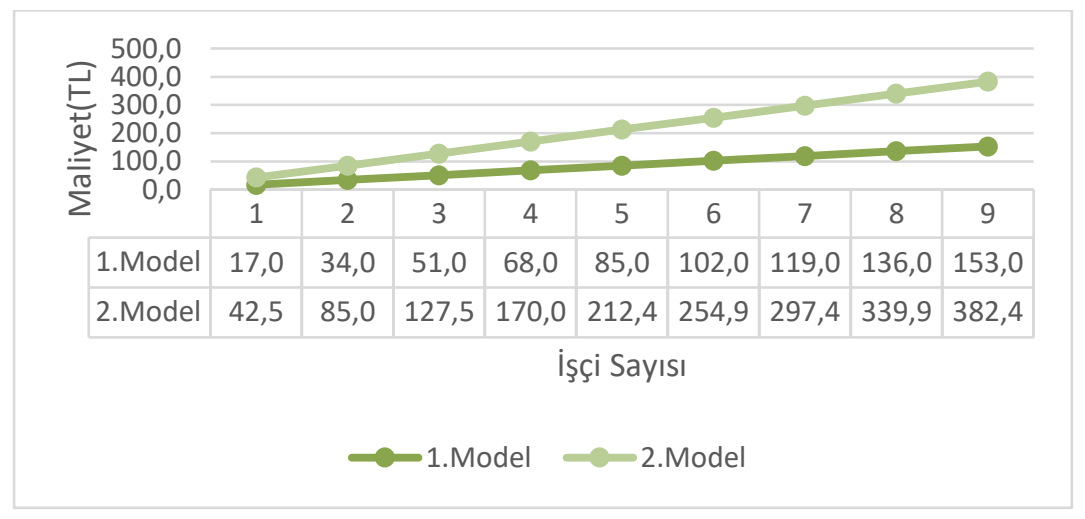

Şekil 4. Modellerin Maliyet Yönüyle Karşılaştırılması

Şekil 4' teki grafikte x ekseninde işçi sayıları, y ekseninde ise işçilerin zaman kayıplarından oluşan işçilik maliyetleri verilmiştir. 1. model ile her bir taşıma aracı için sabit bir yerleşim sonucunda bir son ürün için haftalık 153 TL'lik işçilik maliyetinin büyük çoğunluğundan tasarruf sağlanacağı belirlenmiştir. 2. model vasıtasıyla hem her bir taşıma aracının sabit bir yerleşimi hem de parçaların dağınık yerleşimi sebebiyle taşımadan kaynaklı süre kayıpları önlenerek toplamda haftalık 382,4 TL'lik işçilik maliyetinin büyük çoğunluğundan tasarruf sağlanacağı hesaplanmıştır. Kasa-raf ve kasa-koridor modellerinin sonucunda, koridorlar için elde edilen doluluk oranları Tablo 5’te belirtildiği gibidir. Raf doluluk oranı yönlü yapılan kıyaslamada, Model 2 ile ortalama \%78,47'lik yüksek bir doluluk oranı sağlanmıştır.

Tablo 5. Kasa-Raf ve Kasa-Koridor Modelleri İçin Doluluk Oranları

\begin{tabular}{ccccc}
\hline & \multicolumn{4}{c}{ Doluluk Oranlar1 (\%) } \\
\hline & 1.Koridor & 2.Koridor & 3.Koridor & Ortalama \\
\hline Model 1 & 87,19 & 76,04 & 65,52 & 76,25 \\
\hline Model 2 & 74,79 & 86,67 & 73,96 & 78,47 \\
\hline
\end{tabular}




\section{Sonuç}

Bu çalışmada, her iki modelin çözümüyle de sabit bir yerleşim düzeni oluşturmak amaçlanmıştır. İlk model ile raflardaki parça çeşitliliği en küçüklenerek işçinin aynı parçaya ait taşıma araçlarını bulması kolaylaştırılmıştır. İkinci modelde ise, parçalara ait taşıma araçlarının aynı koridorda yer aldığı bir yerleşim sistemi ile işçinin hem taşıma aracını bulması kolaylaşmış hem de taşıma mesafesi en küçüklenmiştir. İlk modelin yerleşim düzeni incelendiğinde, taşıma araçlarının tüm koridorlara dağıldığı dikkati çekmektedir. İkinci model yerleşiminde ise, bu durumun önüne geçildiği açık bir şekilde görülmektedir. Bu nedenle, önerilen ikinci model ile daha etkin bir yerleşim düzeni oluşturulduğu anlaşılmaktadır. Ayrıca, \%78,47’lik doluluk oranıyla ikinci modelin daha etkin olduğu görülmektedir. $\mathrm{Bu}$ yerleşim düzeni ile yalın üretim kapsamında firmada yapılacak çalışmalara örnek teşkil edecek bir sistem oluşturulmuştur. Aynı zamanda üretim içinde belirli bir yerleşim düzeninin sağlanacağı ve kullanılmayan parçaların üretim içerisinde bulunması engelleneceği için 5S çalışmalarına önemli bir katkı sağlamıştır. Mevcut durumda barkod sistemi bulunmadığı için parçaya istenilen zamanda ulaşılamazken, önerilen sistem ile bu eksikliğin dezavantajları giderilmeye çalışılmıştır. Geliştirilecek kart sistemi ile her bir parçanın kimliği oluşturularak taşıma araçlarının depolanacağı noktalara yerleştirilmesi düşünülmektedir. Bu kimlikler, hem parçanın taşıma aracında hem de raflarda yer almalıdır bu sayede işçinin taşıma araçlarını raflara yerleştirirken oluşacak zaman kaybı en aza indirilebilecektir.

\section{Kaynakça}

Chabot, T., Lahyani, R., Coelho, L.C., \& Renaud J. (2015). Order Picking Problems under Weight, Fragility and Category Constraints. CIRRELT- 2015- 49, 1-29.

Çolak M., Aydın Keskin G., Günel G., \& Akkaya D. (2016). Bir kimya firmasında hammadde deposunun etkin yerleşimi için bir model önerisi. Beykent Üniversitesi Fen ve Mühendislik Bilimleri Dergisi, 9(2), 55-76.

Denizhan B., \& Menşur Ş. (2019). Bir lastik fabrikasında dinamik adresleme yaklaşımı ile depoya yerleştirme. Academic Platform Journal of Engineering and Science, 7(3), 481-488.

Frazelle, E. H., \& Sharp, G. P. (1989). Correlated assignment strategy can improve any order picking operation. Industrial Engineering, 21, 33-37.

Gül, G., Erol, B., Öngelen, G., Eser, S., Çetinkaya Ç., Özmutlu, H. C., Özmutlu, S., Gökçedağlığlu, M., \& Erhuy, C. G. (2016). Ambar depolama maksimizasyonu. Endüstri Mühendisliği Dergisi, 27(4), 26-38.

Heragu, S.S., Du L., Mantel, R.J. \& Schuur, P. C. (2005). Mathematical model for warehouse design and product allocation. International Journal of Production Research, 43(2), 327-338.

Kırış Ş. (2013). Multi-criteria inventory classification by using a fuzzy analytic network process (ANP) approach. Informatica, 24(2), 199-217.

Kulaç S., \& Çağıl G. (2019). Bir iç lojistik sistem probleminin, araç rotalama çözüm yöntemleri ile iyileştirilmesi. Uluslararası Mühendislik Araştırma ve Geliştirme Dergisi, 11(2), 528-541.

Küçükoğlu, İ., Yağmahan, B., Çağlıyan, M.S., Yıldız, A., \& Aktokluk D. (2018). İç lojistik sisteminde malzeme tedariği için geliştirilmiş matematiksel modelleme yaklaşımı: Bir uygulama. Uludağ Üniversitesi Mühendislik Fakültesi Dergisi, 23(4), 159-173. doi: 10.17482/uumfd.455198.

Le-Duc, T. (2005). Design and contol of efficient order picking processes. Doktora Tezi, Erasmus Research Institute of Management, Rotterdam, 12-16.

Öztürk, Z. K., Akyol Özer, E., Gülen Ç., Çiçek, A., \& Serttaş, M. D. (2019) Mathematical and heuristic solution approaches for shelf assignment problem in multiple warehouses. Endüstri Mühendisliği, 30(1), 63-74.

Öztürkoğlu Ö., \& Hoşer D. (2018). Yeni bir depo tasarım problemi ve polinomsal zamanlı optimal sipariş toplama algoritması önerisi. Gazi Üniversitesi Mühendislik-Mimarlık Fakültesi Dergisi, 33(4), 1569-1588.

Öztürkoğlu Ö., Kocaman Y., \& Gümüşoğlu Ş. (2018). Çok kapılı birim yük depolarda Chevron koridor tasarımının değerlendirilmesi. Gazi Üniversitesi Mühendislik-Mimarlık Fakültesi Dergisi, 33(3), 793-807.

Petersen C. G. (1997). An Evaluation of Order Picking Routing Policies. International Journal of Operations and Production Management, 17(11), 1098-1111. doi/ 10.1108/01443579710177860.

Petersen C. G., \& Aase G. R. (2017). Improving Order Picking Efficiency with the Use of Cross Aisles and Storage Policies. Open Journal of Business and Management, 5, 95-104. doi: 10.4236/ojbm.2017.51009.

Sert, M., \& Kesen, S.E. (2019). Tam zamanında üretim felsefesine dayalı bir seri üretim hattının simülasyon tekniğiyle performans analizi. Selçuk Üniversitesi Mühendislik, Bilim ve Teknoloji Dergisi, 7(1), 115-134. doi: 10.15317/Scitech.2019.186.

Seval, İ. (2018). Lojistik ve tedarik zinciri yönetiminde talep hacmi, depo ve filo işletme planlaması. Yüksek Lisans Tezi, Maltepe Üniversitesi Sosyal Bilimler Enstitüsü, İstanbul, 57-59.

Surjandari. I., Rachman, A., \& Lusiani, M. (2012). Optimization of products shelf space allocation based on product price using multilevel association rules. 2nd International Conference on Industrial Technology and Management, IPCSIT. 49, 62-65. doi: 10.7763/IPCSIT.2012.V49.12

Tekil, S., \& Özkır, V.Ç. (2016). Konteyner yükleme problemlerinin incelenmesi ve lojistik sektöründe bir uygulama. Toros Üniversitesi Sosyal Bilimler Dergisi, 3(5), 213-223.

Tunç, S., Kutlu B., Zincidi, A., \& Atmaca, E. (2008). Depo sisteminde sipariş toplama sürecinin iyileştirilmesi. Gazi Üniversitesi Mühendislik-Mimarlık Fakültesi Dergisi, 23(2), 357-364.

Yener, F., \& Yazgan, H.R. (2019). Optimal warehouse design: Literature review and case study application. Computers \& Industrial Engineering, 129, 1-13. doi: 10.1016/j.cie.2019.01.0 
Yılmaz Yalçıner A., \& Can B. (2019). Tam sayılı programlama ve simülasyon ile raf alanı optimizasyonu: bir ambalaj firmasında uygulama. Avrupa Bilim ve Teknoloji Dergisi Özel Sayı, 375-388.

Zhou W., Piramuthu S., \& Chu F. (2017). RFID enabled flexible warehousing. Decision Support Systems, 98, 99-112.

EK-1: Model-1 Sonuçlarına Göre Elde Edilen Yerleşim Ataması

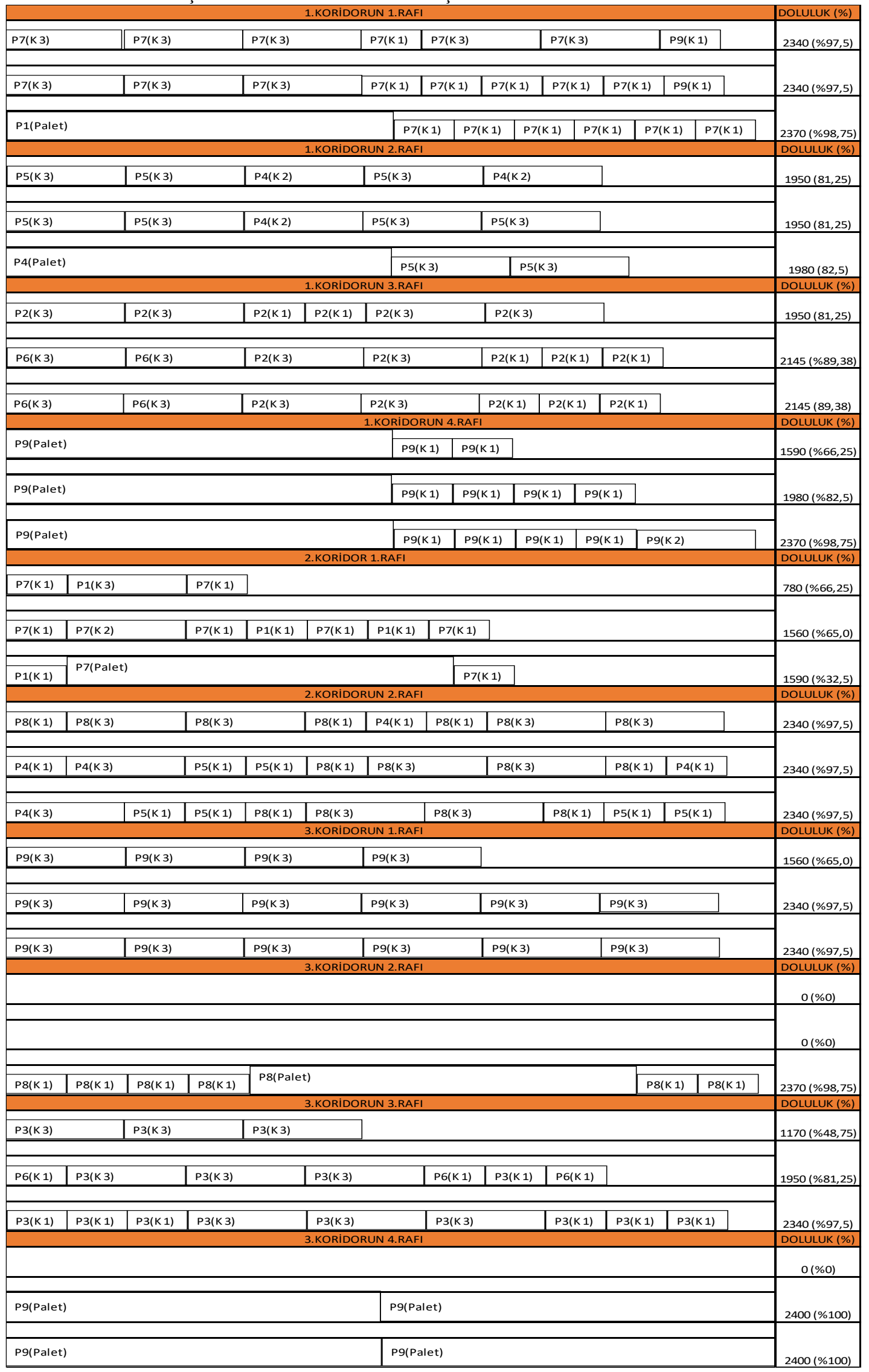


EK-2: Model-2 Sonuçlarına Göre Elde Edilen Yerleşim Ataması

\begin{tabular}{|c|c|c|c|c|c|c|c|c|c|c|c|c|}
\hline & & & & $1 . \mathrm{KO}$ & RIDORUN 1 & RAFI & & & & & & Doluluk (\%) \\
\hline & & & & & & P8 (Palet & & & & & & 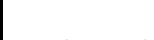 \\
\hline $\mathrm{P} 1$ (K 1) & P7 (K 3) & & P7 (K 3) & & P8 (K 1) & & & & & & & $2370(\% 98,75)$ \\
\hline $\mathrm{P} 1$ (K 1) & P5 (K 3) & & P7 (K 3) & & P7 (K 3) & & P7 (K 3) & & P8 (K 1) & P5 (K 3) & & $2340(\% 97,5)$ \\
\hline P1 (K 1) & P5 (K 3) & & P7 (K 3) & & P7 (K 3) & & P7 (K 3) & & P8 (K 1) & P5 (K 3) & & $2340(\% 97,5)$ \\
\hline & & & & 1.KORIDO & RUN 2.RAF & & & & & & & Doluluk (\%) \\
\hline P5 (K 3) & & P7 (K 1) & P7 (K 1) & P7 (K 1) & P7 (K 1) & P7 (K 1) & P7 (K 1) & P8 (K 1) & P8 (K 1) & $\mathrm{P} 5(\mathrm{~K} 3)$ & & $2340(\% 97,5)$ \\
\hline & & & & & & & & & & $P 5(K 3)$ & & \\
\hline P5 (K 3) & & P7 (K 1) & P7 (K 1) & $\mathrm{P} 7(\mathrm{~K} 1)$ & $\mathrm{P} 7$ (K 1) & P7 (K 1) & P7 (K 1) & P8 (K 1) & P8 (K 1) & P8 (K 1) & P8 (K 1) & $2340(\% 97,5)$ \\
\hline P5 (K 3) & & P7 (K 1) & P7 (K 1) & P7 (K 1) & P7 (K 1) & P7 (K 1) & P7 (K 1) & P8 (K 1) & P8 (K 1) & P8 (K 1) & P8 (K 1) & $2340(\% 97,5)$ \\
\hline & & & & 1.KORIDO & RUN 3.RAF & & & & & & & Doluluk (\%) \\
\hline & & & & & & & & & & & & $0(\% 0)$ \\
\hline P5 (K 1) & P5 (K 1) & P5 (K 1) & P5 (K 1) & & & & & & & & & $780(32,5)$ \\
\hline & & & & & P7(Palet & & & & & & & \\
\hline $\mathrm{P} 1(\mathrm{~K} 3)$ & & P5 (K 1) & P7(K2) & & & & & & & & & $2370(\% 98,75)$ \\
\hline & & & & 1.KORIDO & RUN 4.RAF & & & & & & & Doluluk (\%) \\
\hline $\mathrm{P} 8(\mathrm{~K} 3)$ & & P8(K3) & & & & & & & & & & $780(\% 32,5)$ \\
\hline $\mathrm{P} 8(\mathrm{~K} 3)$ & & $\mathrm{P} 8(\mathrm{~K} 3)$ & & $\mathrm{P} 8(\mathrm{~K} 3)$ & & & & & & & & $1170(\% 48,75)$ \\
\hline & & & & & & P1(Palet) & & & & & & \\
\hline $\mathrm{P} 8(\mathrm{~K} 3)$ & & P8(K 3) & & $\mathrm{P} 8(\mathrm{~K} 3)$ & & & & & & & & $2370(\% 98,75)$ \\
\hline & & & & & ORIDOR 1. & ZAFI & & & & & & Doluluk (\%) \\
\hline P2 (K 1) & $\mathrm{P} 2$ (K 1) & P6 (K 1) & $\mathrm{P} 2(\mathrm{~K} 3)$ & & P3 (K 1) & $\mathrm{P} 6(\mathrm{~K} 3)$ & & $P 6(K 3)$ & & & & $1950(\% 81,25)$ \\
\hline $\mathrm{P} 2$ (K 1) & $\mathrm{P} 2$ (K 1) & P2 (K 1) & $\mathrm{P} 2(\mathrm{~K} 3)$ & & P3 (K 1) & $\mathrm{P} 6$ (K 1) & P6(K3) & & $\mathrm{P6}(\mathrm{K} 3)$ & & & $2145(\% 89,38)$ \\
\hline P2 (K 1) & $\mathrm{P} 2$ (K 1) & P2 (K 1) & $\mathrm{P} 2(\mathrm{~K} 3)$ & & P3 (K 1) & $\mathrm{P} 6$ (K 1$)$ & P6(K 3$)$ & & $\mathrm{P} 6(\mathrm{~K} 3)$ & & & $2145(\% 89,38)$ \\
\hline & & & & 2.KORID & OR 2.RAFI & & & & & & & Doluluk (\%) \\
\hline $2(\mathrm{~K} 3)$ & & $3(\mathrm{~K} 3)$ & & $3(\mathrm{~K} 3)$ & & $3(\mathrm{~K} 3)$ & & & & & & $1560(\% 65,0)$ \\
\hline $2(\mathrm{~K} 3)$ & & $2(\mathrm{~K} 3)$ & & $3(K 1)$ & $3(K 1)$ & $3(\mathrm{~K} 3)$ & & $3(\mathrm{~K} 3)$ & & $3(\mathrm{~K} 3)$ & & $2340(\% 97,5)$ \\
\hline $2(\mathrm{~K} 3)$ & & $2(\mathrm{~K} 3)$ & & $3(\mathrm{~K} 1)$ & $3(\mathrm{~K} 1)$ & $3(\mathrm{~K} 3)$ & & $3(\mathrm{~K} 3)$ & & $3(\mathrm{~K} 3)$ & & $2340(\% 97,5)$ \\
\hline & & & & $3 . \mathrm{KO}$ & RIDORUN 1 & RAFI & & & & & & \begin{tabular}{|l|} 
Doluluk (\%) \\
\end{tabular} \\
\hline $\mathrm{Pg}(\mathrm{K} 3)$ & & $\mathrm{Pg}(\mathrm{K} 3)$ & & $\mathrm{Pg}(\mathrm{K} 3)$ & & & & & & & & $1170(\% 48,75)$ \\
\hline $\mathrm{P} 4(\mathrm{~K} 2)$ & & P4(K 3) & & $\mathrm{P} 4(\mathrm{~K} 2)$ & & P9(K 3$)$ & & $\mathrm{Pg}(\mathrm{K} 3)$ & & $\mathrm{Pg}(\mathrm{K} 3)$ & & $2340(\% 97,5)$ \\
\hline $\mathrm{P} 4(\mathrm{~K} 2)$ & & P4(K 3) & & $\mathrm{Pg}(\mathrm{K} 2)$ & & $\mathrm{Pg}(\mathrm{K} 3)$ & & $\mathrm{Pg}(\mathrm{K} 3)$ & & $\mathrm{Pg}(\mathrm{K} 3)$ & & $2340(\% 97,5)$ \\
\hline & & & & 3.KORIDO & RUN 2.RAF & & & & & & & Doluluk (\%) \\
\hline$P 9(K 3)$ & & $\mathrm{P9}(\mathrm{K} 1)$ & $\mathrm{P9}(\mathrm{K} 1)$ & $\mathrm{Pg}(\mathrm{K} 1)$ & P9 (K 1) & P9(K3) & & & & & & $1560(\% 65,0)$ \\
\hline $\mathrm{P9}(\mathrm{K} 3)$ & & P9 (K 1) & P9 (K 1) & $\mathrm{Pg}$ (K 1) & P9 (K 1) & $\mathrm{Pg}(\mathrm{K} 3)$ & & & & & & $1560(\% 65,0)$ \\
\hline & & & & & & P9(Palet) & & & & & & \\
\hline $\mathrm{Pg}(\mathrm{K} 1)$ & $\mathrm{Pg}$ (K 1) & $P 9(K 1)$ & $\mathrm{Pg}$ (K 1) & $\mathrm{Pg}(\mathrm{K} 3)$ & & & & & & & & $2370(\% 98,75)$ \\
\hline & & & & 3.KORIDO & RUN 3.RAF & & & & & & & Doluluk (\%) \\
\hline & & & & & & & & & & & & $0(\% 0)$ \\
\hline P9(Palet & & & & & & & Palet) & & & & & $2400(\% 100)$ \\
\hline P4(Palet & & & & & & & Palet) & & & & & \\
\hline & & & & 3.KORIDO & RUN 4.RAF & & & & & & & \begin{tabular}{|l|} 
Doluluk (\%) \\
\end{tabular} \\
\hline P4 (K 1) & $\mathrm{Pg}(\mathrm{K} 3)$ & & & & & & & & & & & $585(\% 24,38)$ \\
\hline & & & & & P9(Palet & & & & & & & \\
\hline$P 4(K 1)$ & $\mathrm{Pg}(\mathrm{K} 1)$ & P4 (K 1) & $\mathrm{Pg}(\mathrm{K} 3)$ & & & & & & & & & $2175(\% 90,63)$ \\
\hline P9(Palet & & & & & & & Palet) & & & & & $2400(\% 100)$ \\
\hline
\end{tabular}

